\title{
Variable Torque Control of Offshore Wind Turbine on Spar Floating Platform Using Advanced RBF Neural Network
}

\author{
Lei Wang, ${ }^{1,2}$ Shan Zuo, ${ }^{2}$ Y. D. Song, ${ }^{1,2}$ and Zheng Zhou ${ }^{3}$ \\ ${ }^{1}$ Intelligent Systems and New Energy Technology Research Institute, Chongqing University, Chongqing 400044, China \\ ${ }^{2}$ Institute of Intelligent System and Renewable Energy Technology, University of Electronic Science and Technology of China, \\ Chengdu 611731, China \\ ${ }^{3}$ Web Science Center, University of Electronic Science and Technology of China, Chengdu 611731, China
}

Correspondence should be addressed to Lei Wang; leiwang08@cqu.edu.cn

Received 2 January 2014; Revised 14 January 2014; Accepted 15 January 2014; Published 6 March 2014

Academic Editor: Xiaojie Su

Copyright (C) 2014 Lei Wang et al. This is an open access article distributed under the Creative Commons Attribution License, which permits unrestricted use, distribution, and reproduction in any medium, provided the original work is properly cited.

Offshore floating wind turbine (OFWT) has been a challenging research spot because of the high-quality wind power and complex load environment. This paper focuses on the research of variable torque control of offshore wind turbine on Spar floating platform. The control objective in below-rated wind speed region is to optimize the output power by tracking the optimal tip-speed ratio and ideal power curve. Aiming at the external disturbances and nonlinear uncertain dynamic systems of OFWT because of the proximity to load centers and strong wave coupling, this paper proposes an advanced radial basis function (RBF) neural network approach for torque control of OFWT system at speeds lower than rated wind speed. The robust RBF neural network weight adaptive rules are acquired based on the Lyapunov stability analysis. The proposed control approach is tested and compared with the NREL baseline controller using the "NREL offshore $5 \mathrm{MW}$ wind turbine" model mounted on a Spar floating platform run on FAST and Matlab/Simulink, operating in the below-rated wind speed condition. The simulation results show a better performance in tracking the optimal output power curve, therefore, completing the maximum wind energy utilization.

\section{Introduction}

Wind energy has been an important part of the renewable energy. It is significantly meaningful for optimizing the energy system structure, easing the energy crisis, and protecting the environment by actively developing wind energy. With the rapidly development of wind energy all over the world, promising and reliable wind turbine concepts have been developed. Offshore wind turbine makes it possible to go further into water deeper than $60 \mathrm{~m} \mathrm{[1]}$; therefore, it has become the key research in the field of renewable energy.

The floating offshore wind turbine (OFWT) concept provides a groundbreaking strategy to fully utilize the highquality wind power in deep waters. The design concept of "large floating offshore wind turbine" was firstly proposed by Heronemus from Massachusetts Institute of Technology (MIT) in 1972 [2, 3]. American Renewable Energy
Laboratory (NREL) and MIT have completed the dynamic system modeling of OFWT and the three types of floating platform: tension leg platform with suction pile anchors, Spar-buoy with catenary mooring, drag-embedded anchors and barge with catenary mooring lines through OC3 projects [4]. Figure 1 shows the three primary types of floating offshore wind turbine concepts.

Previous research results show that, compared to onshore wind turbines, OFWTs with six degrees of freedom are prone to pitching motion and to produce complex dynamic load because of proximity to load centers and strong wave coupling [5]. Meanwhile, with the larger scale (the capacity of OFWTs reaches up to $10 \mathrm{MW}$, the diameter of blades approximates 200 meters), the blades of OFWT produce higher uneven loads due to the effect of turbulence, wind shear, tower shadow, and spindle tilt. Accumulating of the above two types of loads will result in devastating impact on the fatigue life and output power quality of the OFWT system. 


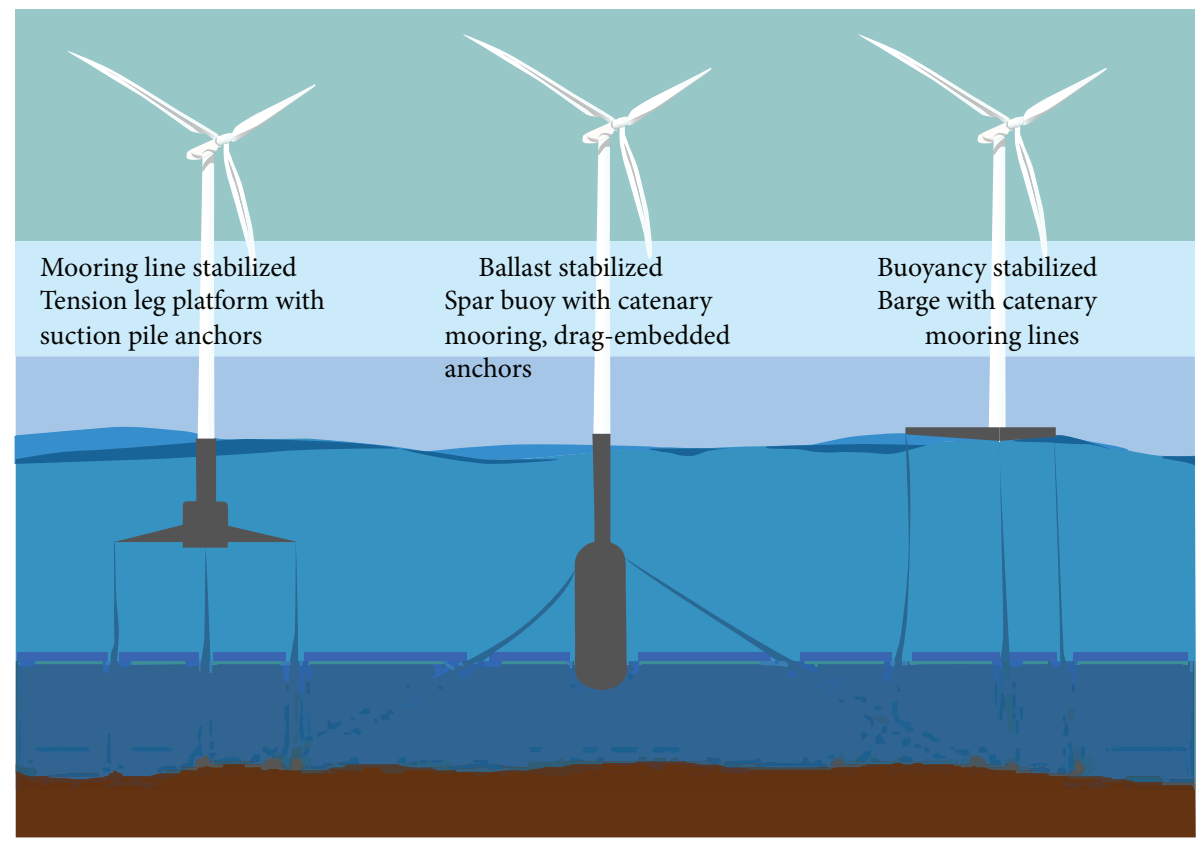

FIGURE 1: Floating offshore wind turbine concepts (image from Google).

Therefore, it is urgently needed to reduce fatigue loads and improve output power quality for OFWT system by utilizing advanced control strategies.

Control of OFWT is a relatively new yet challenging research area. There have been a large number of recent achievements in the research of blade pitch control for OFWT in the above-rated wind speed region [6-13]. In our previous work [6], we propose a computationally inexpensive robust adaptive control approach with memory-based compensation for blade pitch control. However, works on the variable speed control for OFWT system in below-rated wind speed region are relatively few.

In this study, to address the challenge that the system parameters of OFWT are varying and uncertain due to the complex external wind and wave disturbances, an adaptive radial basis function ( $\mathrm{RBF}$ ) neural network approach is proposed for torque control of OFWT system at speeds lower than rated wind speed. The robust RBF neural network weight adaptive rules are acquired based on the Lyapunov stability analysis. The proposed torque controller based on RBF neural network is presented and mounted on a Spar floating platform for performance comparison with the baseline torque controller in the below-rated wind speed region.

Section 2 briefly presents the wind turbine model and the Spar floating platform utilized in this paper. Section 3 describes the two implemented controllers: the baseline torque controller and the proposed variable torque controller based on RBF neural network. Section 4 shows the simulation and results, in which performances of the above two controllers are compared with each other on Spar floating platform. Eventually, conclusions are reported in Section 5.

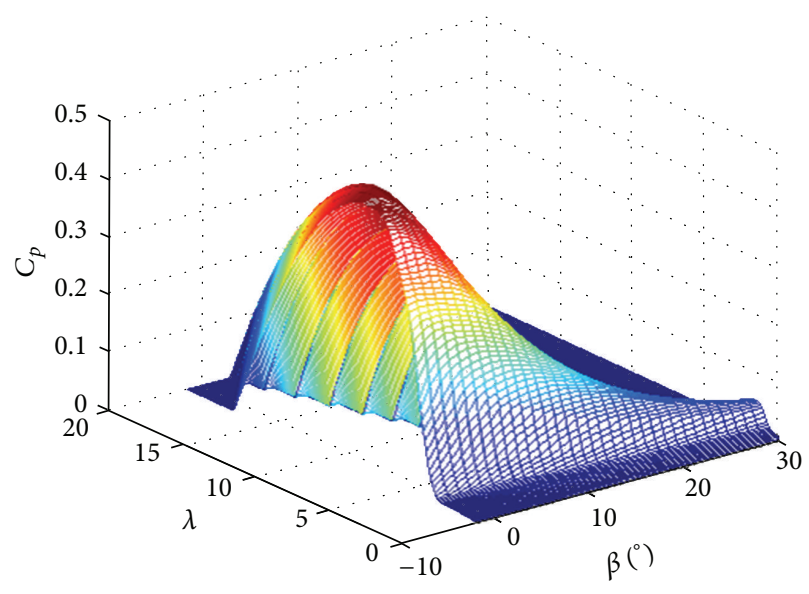

FIGURE 2: Power coefficients for VSVP wind turbine.

\section{Wind Turbine and Platform Models}

2.1. 5 MW Offshore Wind Turbine Model. The basic properties of future offshore turbines can be estimated by considering the amount of kinetic energy density in the wind, which can be converted into kinetic energy of the turbine shaft. The expression for power produced by the wind is simply given by

$$
P_{S}=\frac{1}{2} C_{p}(\lambda, \beta) \rho A v^{3},
$$

where $\rho$ is air density and $A$ is the swept area of the turbine rotor with a radius $R$, giving $A=\pi R^{2} . v$ is wind speed passing the rotor. $C_{p}$ denotes power coefficient of wind turbine, which is a nonlinear function of the tip-speed ratio $\lambda$ and the pitch angle $\beta$ [14]. Figure 2 depicts the curve of 
power coefficients for variable speed and variable pitch wind turbine. It indicates that, for a different $\beta$, there will be a different curve for the $C_{p}-\lambda$, while, for a fixed $\beta$, there will be an optimal $\lambda$ at which the power output is maximum. In addition, for any tip-speed ratio $\lambda$, power coefficient $C_{p}$ is relatively maximum when blade pitch angle $\beta=0^{\circ}$. When $\beta$ increases, $C_{p}$ decreases simultaneously.

Note that the tip-speed ratio is defined as

$$
\lambda=\frac{v_{\text {Tip }}}{v}=\frac{R \omega_{r}}{v},
$$

where $v_{\text {Tip }}$ is the tip speed and $\omega_{r}$ is the rotor speed.

For a constant value of $\beta=0^{\circ}$, the mathematical model of $C_{p}$ is expressed as

$$
\begin{gathered}
C_{p}(\lambda)=c_{1}\left(\frac{c_{2}}{\lambda_{1}}-c_{4}\right) e^{-c_{5} / \lambda_{1}}+c_{6} \lambda, \\
\frac{1}{\lambda_{1}}=\left(\frac{1}{\lambda}-0.035\right),
\end{gathered}
$$

where the coefficients $\left(c_{1}, c_{2}, c_{4}, c_{5}, c_{6}\right)$ depend on the aerodynamic design of the blade and operating conditions of the wind turbine. In this paper, the coefficients are $c_{1}=0.5176$, $c_{2}=116, c_{4}=5, c_{5}=21$, and $c_{6}=0.0068$ [15]. For the "NREL $5 \mathrm{MW}$ reference offshore wind turbine" model simulated in this paper, the peak power coefficient of 0.482 occurred at a tip-speed ratio of 7.55 and a rotor-collective blade-pitch angle of $0.0^{\circ}$ [16].

In the case of the variable speed wind power generation system, the maximum power point control from the wind turbine can be adopted. The maximum power of the wind turbine is given by

$$
P_{\max }=\frac{1}{2} \frac{\rho \pi R^{5} C_{p_{-} \max }}{\lambda^{* 3}} \omega_{r}^{* 3} .
$$

The physical properties of the specified wind turbine model used for analysis, the "NREL 5 MW reference offshore wind turbine," are listed in Table 1 [16]. This wind turbine is mounted on a Spar floating platform.

2.2. Floating Platform. The Spar-buoy platform is modeled for the support structure. The NREL $5 \mathrm{MW}$ offshore floating platform input properties for the OC3-Hywind Spar-buoy used in this paper are briefly summarized in Table 2 [4].

\section{Implemented Controllers}

This section gives the detailed information about the two controllers simulated in the analysis.

3.1. The Baseline Generator Torque Controller. The baseline generator torque controller is built on the best performance presented by Jonkman in his previous research on the Sparbuoy platform [17].

In the below rated wind speed region, the purpose is to optimize power capture. The generator torque is proportional

TABLE 1: NREL $5 \mathrm{MW}$ turbine model properties.

Power rating

Rotor orientation, Configuration

Control

Rotor, hub diameter

Hub height

Cut-in, rated, cut-out wind speed

Rated rotor, generator speed

Rotor mass

Optimal tip-speed-ratio

Blade operation

Maximum blade pitch rate

Rated generator torque

Maximum generator torque

Using the turbine model data from [16].

TABLE 2: Physical properties for the OC3-hywind spar-buoy.

\begin{tabular}{lc}
\hline Diameter & $6.5 \mathrm{~m}$ \\
Draft & $120.0 \mathrm{~m}$ \\
Platform mass & $7,466,330 \mathrm{~kg}$ \\
Water depth & $320.0 \mathrm{~m}$ \\
Number of mooring lines & 3 \\
\hline
\end{tabular}

Using the barge platform data from [4].

to the square of the filtered generator speed to maintain a constant optimal tip-speed ratio.

The generator torque for this region is expressed as

$$
T_{g}^{\omega_{r}}=T_{g}^{1}+\frac{T_{g}^{*}-T_{g}^{1}}{\omega_{r, 2}-\omega_{r, 1}}\left(\omega_{r}-\omega_{r, 1}\right)
$$

where $\omega_{r}$ is rotor speed, $T_{g}^{1}$ is the generator torque at the rotor speed in which this region starts $\left(\omega_{r, 1}\right), T_{g}^{*}$ is rated torque, and $\omega_{r, 2}$ is the rotor speed in which the rated torque is reached.

3.2. Advanced Generator Torque Controller Based on RBF Neural Network. We propose a RBF neural network for variable torque control of the OFWT system. The total number of input signals in the OFWT torque control system is no more than 4. Consequently, it is a computationally inexpensive approach to utilize the RBF neural network for linearization and approximation.

In this paper, the RBF neural network is a three-layer forward network, including an input layer, a hidden layer with a Gaussian activation function, and a linear output layer. The mapping from input to output is nonlinear, while the mapping from hidden layer to output layer is linear, therefore speeding up the process of study obviously and avoiding local minimum problem. The topological structure of RBF network is presented in Figure 3.

The control block diagram of RBF neural network is illustrated in Figure 4. 


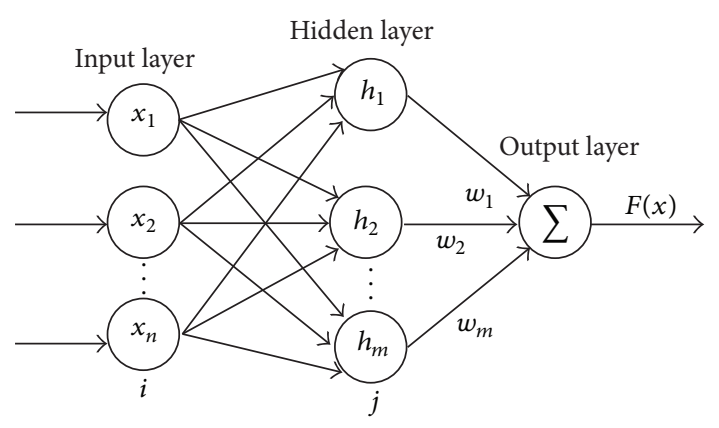

FIGURE 3: Topological graph of RBF neural network.

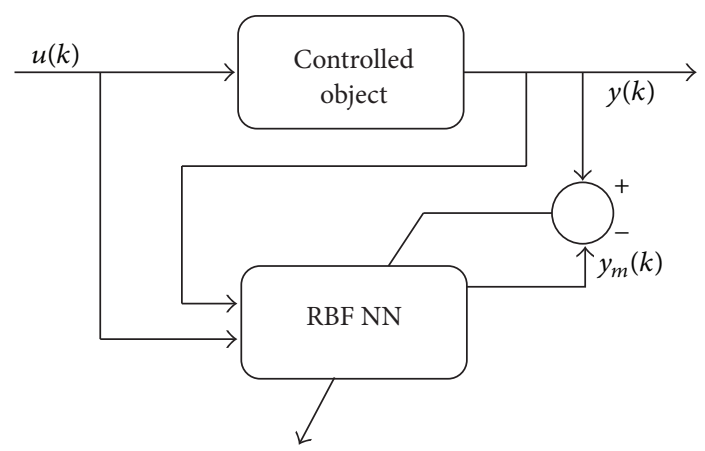

FIGURE 4: Control block diagram of RBF neural network.

In RBF network, $X=\left[x_{1}, x_{1}, \ldots, x_{n}\right]^{T}$ is the input vector, $h_{g}$ is a nonlinear RBF activation function, which is given by

$$
\begin{array}{r}
h_{g}=\Phi\left(\left\|X-C_{g}\right\|\right)=\exp \left(-\frac{\left\|X-C_{g}\right\|^{2}}{2 b_{g}^{2}}\right), \\
g=1,2, \ldots, m,
\end{array}
$$

where $m$ is the number of neurons in the hidden layer and $C_{g}=\left[c_{1 g}, c_{2 g}, \ldots, c_{i g}, \ldots, c_{n g}\right]^{T}$ is the central vector of $g$ th hidden neuron. $B=\left[b_{1}, b_{2}, \ldots, b_{g}, \ldots, b_{m}\right]^{T}$ is the basis-width vector, $b_{g}>0$ is the base width constant of $g$ th mode, and the weight vector of the linear output neurons is $w=$ $\left[w_{1}, w_{2}, \ldots, w_{g}, \ldots, w_{m}\right]^{T}$.

The output $R^{n} \rightarrow R$ of the neural network is defined as

$$
F(x)=w H=\sum_{g=1}^{m} w_{g} \Phi\left(\left\|x-C_{g}\right\|\right) .
$$

From previous research results [13, 18-25], we could learn that, a RBF neural network with enough hidden neurons can approximate any nonlinear continuous functions with arbitrary precision. In this paper, in order to train the RBF neural network, we utilize the Lyapunov stability to get the weights updating rules of the RBF neural network.

In the first mode of operating at variable torque control, where the wind speed is less than the rated speed region, the electrical torque of the wind turbine must be adjusted to make the rotor speed track the desired speed that is specified

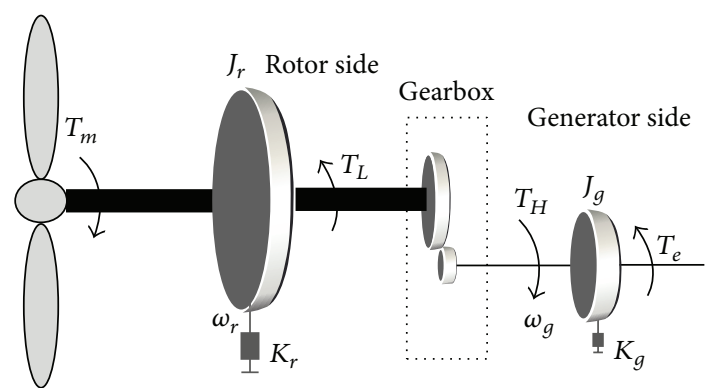

FIGURE 5: Layout of drive train model.

according to the optimal tip-speed ratio. The drive train dynamics are depicted in Figure 5. The mechanical motion equations are given by

$$
\begin{gathered}
J_{r} \dot{\omega}_{r}+K_{r} \omega_{r}+B_{r} \theta_{r}=T_{m}(\omega, \beta, v, \dot{x})-T_{L}, \\
J_{g} \dot{\omega}_{g}+K_{g} \omega_{g}+B_{g} \theta_{g}=T_{H}-T_{e}, \\
n=\frac{\omega_{g}}{\omega_{r}}=\frac{T_{L}}{T_{H}},
\end{gathered}
$$

where $J_{r}$ and $J_{g}$ are the moment of inertia of the rotor and the generator. $K_{r}$ and $K_{g}$ are the coefficient of viscous reaction of rotor and generator, respectively. $B_{r}$ and $B_{g}$ are the coefficient and stiffness of rotor and generator, respectively. $T_{m}, T_{e}, T_{L}$, and $T_{H}$ are the shaft torque at wind turbine end, generator end, and before and after gear box, respectively. $x$ is the tower displacement and $n$ is the gearbox ratio. $\theta_{r}$ and $\theta_{g}$ are the mechanical angular position of the rotor and generator.

We rewrite the above mechanical motion equations in a compact form as follows:

$$
J \dot{\omega}_{r}+K \omega_{r}+B \theta_{r}=T_{m}(\omega, \beta, v, \dot{x})-n T_{e},
$$

where, $B$ are lumped parameters given by

$$
\begin{gathered}
J=J_{r}+n^{2} J_{g}, \\
K=K_{r}+n^{2} K_{g}, \\
B=B_{r}+n^{2} B_{g} .
\end{gathered}
$$

$T_{m}$ is given by

$$
T_{m}=\frac{\rho \pi R^{3} C_{p}(\lambda, \beta)}{2 \lambda}(v-\dot{x})^{2} .
$$

The affine form of the rotor speed equation can be characterized by the following equation:

$$
\dot{\omega}_{r}=\Gamma\left(\omega_{r}, v\right)+\gamma T_{e},
$$

where $\gamma$ is a constant negative value and $T_{e}$ is the input signal, with

$$
\begin{gathered}
\Gamma\left(\omega_{r}, v\right)=\frac{\left(\rho \pi R^{3} C_{p}(\lambda, \beta) / 2 \lambda\right) v^{2}-K \omega_{r}-B \theta_{r}}{J}, \\
\gamma=\frac{-n}{J} .
\end{gathered}
$$


Construct a nonlinear approximation function through RBF neural network given by

$$
\frac{\Gamma\left(\omega_{r}, v\right)}{\gamma}=\Phi\left(\omega_{r}, v\right) w+L\left(\omega_{r}, v\right),
$$

where $\left|L\left(\omega_{r}, v\right)\right| \leq L_{\max }$ represents the lumped RBF neural network approximation error.

To design the rotor speed tracking controller, define the rotor tracking error $e$ as follows:

$$
e=\omega_{r}-\omega_{r}^{*},
$$

where $\omega_{r}^{*}$ is the optimal rotor speed, which is defined as

$$
\omega_{r}^{*}=\frac{\lambda^{*} v}{R},
$$

where the optimum tip speed ratio $\lambda^{*}$ is given in Table 1 .

The control system can be justified by considering the Lyapunov function candidate as follows:

$$
V=\frac{1}{-2 \gamma} e^{2}+\frac{1}{2 \theta_{1}} \widetilde{w}^{T} \widetilde{w},
$$

where $\theta_{1}>0$ is the positive adaptation gain. $\widetilde{w}=w-\widehat{w}$ is the weight error. $w$ and $\widehat{w}$ are the ideal weight and estimated weight of the network, respectively. The Lyapunov function candidate $V$ is a positive definite function and $\dot{V} \leq 0$ is the sufficient condition for the robust stability of the nonlinear system. We can get the following:

$$
\dot{V}=\left(\omega_{r}-\omega_{r}^{*}\right)\left(-\frac{\Gamma\left(\omega_{r}, v\right)}{\gamma}-T_{e}+\frac{\lambda^{*} \dot{v}}{R \gamma}\right)-\frac{1}{\theta_{1}} \widetilde{w}^{T} \dot{\hat{w}} .
$$

Deriving the approximation through the neural networks $\Gamma\left(\omega_{r}, v\right) / \gamma=\Phi\left(\omega_{r}, v\right) w+L\left(\omega_{r}, v\right)$ and $\widehat{\Gamma}\left(\omega_{r}, v\right) / \widehat{\gamma}=\Phi\left(\omega_{r}, v\right) \widehat{w}$. For the stability of the nonlinear system, consider the following controller:

$$
\widehat{u}=T_{e}=-\Phi\left(\omega_{r}, v\right) \widehat{w}+\kappa\left(\omega_{r}-\omega_{r}^{*}\right)+\omega_{r},
$$

where $\kappa>0$ is the rotor speed tracking error feedback gain.

Proof. Based on (18) and (19), we can get

$$
\begin{aligned}
\dot{V}=(\omega & \left.-\omega^{*}\right)\left(-L\left(\omega_{r}, v\right)-\kappa\left(\omega_{r}-\omega_{r}^{*}\right)-\omega_{r}+\frac{\lambda^{*} \dot{v}}{R \gamma}\right) \\
+ & \widetilde{w}^{T}\left(-\Phi^{T}\left(\omega_{r}, v\right)\left(\omega_{r}-\omega_{r}^{*}\right)-\frac{1}{\theta_{1}} \dot{\hat{\omega}}\right) .
\end{aligned}
$$

The weight updating rule of the network can be obtained through the e-modification method given by

$$
\dot{\widehat{w}}=-\theta_{1}\left(\Phi^{T}\left(\omega_{r}, v\right)\left(\omega_{r}-\omega_{r}^{*}\right)+v\left|\omega_{r}-\omega_{r}^{*}\right| \widehat{w}\right),
$$

where $v$ is a constant positive value. Combine (20) and (21) to get the following:

$$
\begin{array}{r}
\dot{V}=\left(\omega_{r}-\omega_{r}^{*}\right)\left(-L\left(\omega_{r}, v\right)-\omega_{r}+\frac{\lambda^{*} \dot{v}}{R \gamma}\right) \\
-\kappa\left(\omega_{r}-\omega_{r}^{*}\right)^{2}+v\left|\omega_{r}-\omega_{r}^{*}\right| \widetilde{w}^{T} \widetilde{w} .
\end{array}
$$

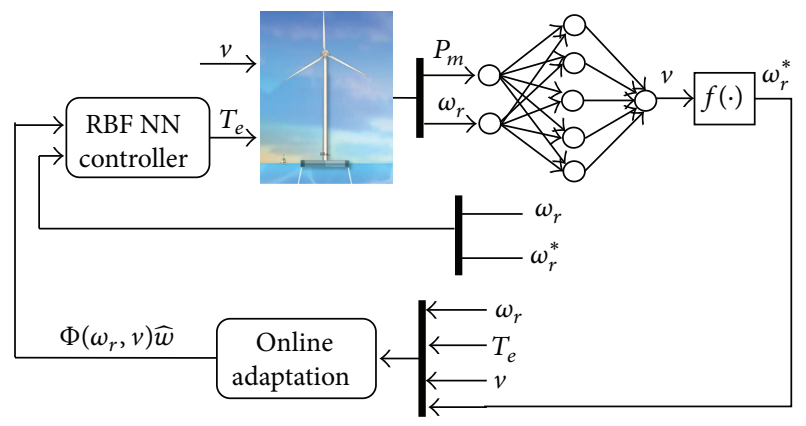

FIGURE 6: Block diagram of the RBF NN variable speed control scheme.

It is assumed that $\omega_{r}$ and $\dot{\omega}_{r}^{*}$ are bounded, so

$$
\begin{gathered}
\left|\omega_{r}\right| \leq L_{1}, \quad\left|\dot{\omega}_{r}^{*}\right|=\left|\frac{\lambda^{*} \dot{v}}{R \gamma}\right| \leq L_{2}, \\
\dot{V} \leq\left|\omega_{r}-\omega_{r}^{*}\right| \\
\cdot\left(\left(L_{\max }+L_{1}+L_{2}\right)-\kappa\left|\omega_{r}-\omega_{r}^{*}\right|-v \widetilde{w}^{T} \widetilde{w}+v \widetilde{w}^{T} w\right) .
\end{gathered}
$$

If $\left|\omega_{r}-\omega_{r}^{*}\right| \geq\left(L_{\max }+L_{w}\right) / \kappa+\left(v w^{2}\right) / 4 \kappa$ or $\|\widetilde{w}\| \geq(w / 2)+$ $\sqrt{\left(L_{\max }+L_{w}\right) / v+w^{2} / 4}$, we could get

$$
\dot{V} \leq 0 .
$$

Therefore, the overall dynamic system is uniformly ultimately bounded.

From the above equations, we can see that the estimated wind speed input enables the generator to track the optimal output power curve by generating a reference rotor speed. There are many previous researches working on estimating wind speed without directly measuring the wind speed. In this paper, we utilize the sensorless scheme presented in [26] to estimate wind speed based on neural network. Then we could get the reference rotor speed by the following equation:

$$
\omega_{r}^{*}=f(v)=\frac{\lambda^{*} v}{R} .
$$

The block diagram of the RBF neural network variable speed control scheme of the OFWT system is depicted in Figure 6.

\section{Simulation and Results}

In this section, the "NREL $5 \mathrm{MW}$ reference offshore wind turbine" installed on a OC3-Hywind Spar-buoy floating platform is tested and simulated with the FAST and MAT$\mathrm{LAB} /$ Simulink under mean value of $8 \mathrm{~m} / \mathrm{s}$ turbulence wind speed, which is below the rated wind speed.

To verify the robustness and self-adaptation of the proposed variable torque controller based on RBF neural network, compared simulations of two types of controllers, 


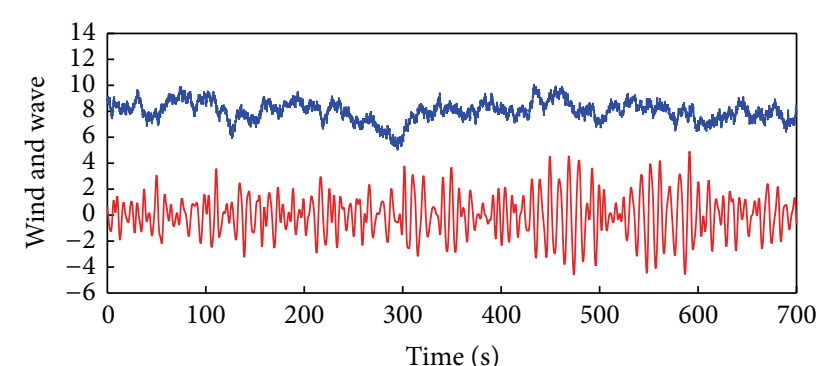

— Wind speed $(\mathrm{m} / \mathrm{s})$

— Wave height $(\mathrm{m})$

FIGURE 7: Wind and wave conditions.

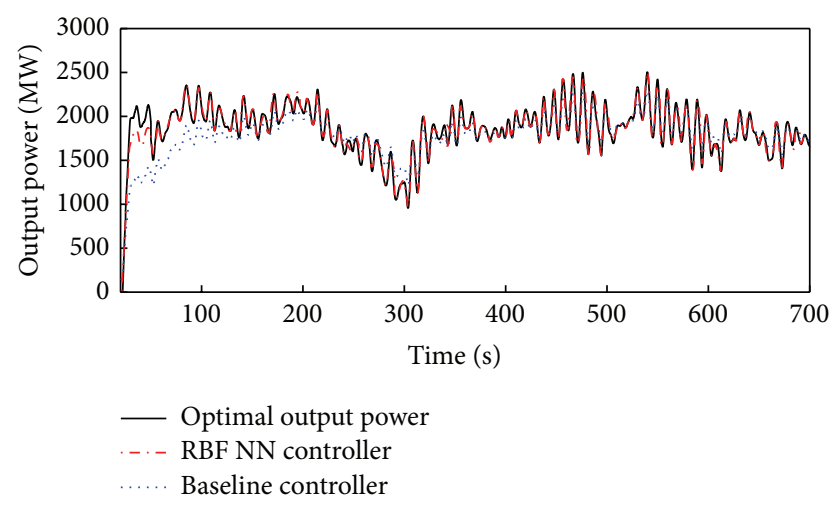

FIGURE 8: Comparison in generator output power.

the baseline torque controller and the proposed torque controller, have been performed on the same offshore wind turbine system. Two comparison performances are simulated based on power tracking: generator output power and torque regulations.

Figure 7 shows the turbulence wind and wave conditions.

Figure 8 compares the average generator output power tracking for the proposed torque controller based on RBF neural network and the baseline torque controller with the optimal output power trajectory. It can be observed that, the proposed adaptive torque controller is able to follow the optimal output power curve with better tracking accuracy than the baseline torque controller, therefore completing the maximum offshore wind energy utilization.

Figure 9 presents the compared curve in generator torque.

\section{Conclusions}

This paper mainly focuses on the variable torque control of OFWT system for power tracking in below-rated wind speed region on a Spar-buoy floating platform. In allusion to the external disturbances and uncertain system parameters of OFWT due to the much more complicated external load environment and strong wave coupling compared to the onshore wind turbine, a robust adaptive torque controller based on RBF neural network is proposed and tested. Two

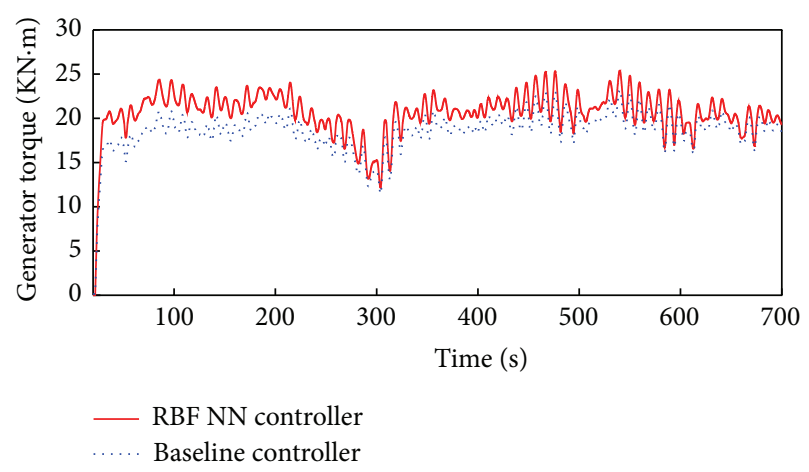

FIgURE 9: Comparison in generator torque.

types of controllers are implemented on the OC3-Hywind Spar-buoy floating platform for performance comparison: the baseline torque controller and the proposed torque controller

According to the average simulation results, the proposed torque controller based on RBF neural network is not only robust to complex wind and wave disturbances but also adaptive to varying and uncertain system parameters as well. As a result, the advanced controller shows a better performance in tracking the optimal generator output power curve, therefore completing the maximum wind energy utilization.

\section{Conflict of Interests}

The authors declare that there is no conflict if interests regarding the publication of this paper.

\section{Acknowledgments}

This work was supported in part by the National High Technology Research and Development Program of China (SS2012AA052302), the National Natural Science Foundation of China (no. 51205046), and the Fundamental Research Funds for the Central Universities (no. CDJZR170008).

\section{References}

[1] F. G. Nielsen, T. D. Hanson, and B. Skaare, "Integrated dynamic analysis of floating offshore wind turbines," in Proceedings of the 25TH International Conference on Offshore Mechanics and Arctic Engineering (OMAE '06), pp. 671-679, Hamburg, Germany, June 2006.

[2] W. E. Heronemus, "Pollution-free energy from offshore wind," in Proceedings of the 8th Annual Conference and Exposition Marine Technology Society, Washington, DC, USA, 1972.

[3] W. Musial and S. Butterfield, "Future for offshore wind energy in the United States," Tech. Rep. 36313, National Renewable Energy Laboratory, Golden, Colo, USA, 2004.

[4] J. M. Jonkman, "Dynamics modeling and loads analysis of an offshore floating wind turbine," Tech. Rep. 41958, National Renewable Energy Laboratory, Golden, Colo, USA, 2007.

[5] J. M. Jonkman and D. Matha, "Dynamics of offshore floating wind turbines-analysis of three concepts," Wind Energy, vol. 14, no. 4, pp. 557-569, 2011. 
[6] S. Zuo, Y. D. Song, L. Wang, and Q.-W. Song, "Computationally inexpensive approach for pitch control of offshore wind turbine on barge floating platform," The Scientific World Journal, vol. 2013, Article ID 357849, 9 pages, 2013.

[7] W. Lei, Y.-L. He, X. Jin, J. Du, and S. Ma, "Dynamic simulation analysis of floating wind turbine," Journal of Central South University: Science and Technology, vol. 43, no. 4, pp. 1309-1314, 2012.

[8] L. Wang, B. Wang, Y. Song et al., "Fatigue loads alleviation of floating offshore wind turbine using individual pitch control," Advances in Vibration Engineering, vol. 12, no. 4, pp. 377-390, 2013.

[9] H. Namik and K. Stol, "Individual blade pitch control of floating offshore wind turbines," Wind Energy, vol. 13, no. 1, pp. 74-85, 2010.

[10] M. A. Lackner, "An investigation of variable power collective pitch control for load mitigation of floating offshore wind turbines," Wind Energy, vol. 16, no. 3, pp. 435-444, 2012.

[11] Y. D. Song, "Control of wind turbines using memory-based method," Journal of Wind Engineering and Industrial Aerodynamics, vol. 85, no. 3, pp. 263-275, 2000.

[12] Y. D. Song, B. Dhinakaran, and X. Bao, "Control of wind turbines using nonlinear adaptive field excitation algorithms," in Proceedings of the IEEE American Control Conference, vol. 3, pp. 1551-1555, Chicago, Ill, USA, 2000.

[13] L. Wu, W. X. Zheng, and H. Gao, "Dissipativity-based sliding mode control of switched stochastic systems," IEEE Transactions on Automatic Control, vol. 58, no. 3, pp. 785-793, 2013.

[14] J. F. Conroy and R. Watson, "Frequency response capability of full converter wind turbine generators in comparison to conventional generation," IEEE Transactions on Power Systems, vol. 23, no. 2, pp. 649-656, 2008.

[15] J. Zaragoza, J. Pou, A. Arias, C. Spiteri, E. Robles, and S. Ceballos, "Study and experimental verification of control tuning strategies in a variable speed wind energy conversion system," Renewable Energy, vol. 36, no. 5, pp. 1421-1430, 2011.

[16] J. Jonkman, S. Butterfield, W. Musial, and G. Scott, "Definition of a 5-MW reference wind turbine for offshore system development," Tech. Rep. TP 500-38060, National Renewable Energy Laboratory, Golden, Colo, USA, 2009.

[17] J. M. Jonkman, "Influence of control on the pitch damping of a floating wind turbine," in Proceedings of the 46th AIAA Aerospace Sciences Meeting and Exhibit, Reno, Nev, USA, January 2008.

[18] R. M. Sanner and J.-J. E. Slotine, "Gaussian networks for direct adaptive control," IEEE Transactions on Neural Networks, vol. 3, no. 6, pp. 837-863, 1992.

[19] Y. Kourd, D. Lefebvre, and N. Guersi, "Fault diagnosis based on neural networks and decision trees: application to DAMADICS," International Journal of Innovative Computing, Information and Control, vol. 9, no. 8, pp. 3185-3196, 2013.

[20] C. K. Ahn and M. K. Song, "New sets of criteria for exponential $L_{2}-L_{\infty}$ stability of Takagi-Sugeno fuzzy systems combined with Hopfield neural networks," International Journal of Innovative Computing, Information and Control, vol. 9, no. 7, pp. 29792986, 2013.

[21] S. Sefriti, J. Boumhidi, M. Benyakhlef, and I. Boumhidi, "Adaptive decentralized sliding mode neural network control of a class of nonlinear interconnected systems," International Journal of Innovative Computing, Information and Control, vol. 9, no. 7, pp. 2941-2947, 2013.
[22] K. S. Narendra and K. Parthasarathy, "Identification and control of dynamical systems using neural networks," IEEE Transactions on Neural Networks, vol. 1, no. 1, pp. 4-27, 1990.

[23] L. Wu, X. Su, P. Shi, and J. Qiu, "Model approximation for discrete-time state-delay systems in the T-S fuzzy framework," IEEE Transactions on Fuzzy Systems, vol. 19, no. 2, pp. 366-378, 2011.

[24] X. Su, Z. Li, Y. Feng, and L. Wu, "New global exponential stability criteria for interval-delayed neural networks," Journal of Systems and Control Engineering, vol. 225, Proceedings of the Institution of Mechanical Engineers, no. 1, pp. 125-136, 2011.

[25] X. Su, P. Shi, L. Wu, and Y.-D. Song, "A novel control design on discrete-time Takagi-Sugeno fuzzy systems with time-varying delays," IEEE Transactions on Fuzzy Systems, vol. 20, no. 6, pp. 655-671, 2013.

[26] H. Li, K. L. Shi, and P. G. McLaren, "Neural-network-based sensorless maximum wind energy capture with compensated power coefficient," IEEE Transactions on Industry Applications, vol. 41, no. 6, pp. 1548-1556, 2005. 


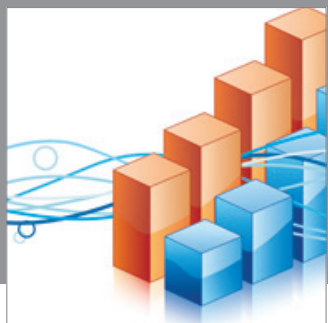

Advances in

Operations Research

mansans

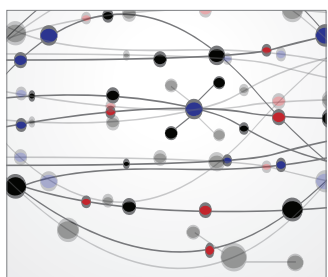

The Scientific World Journal
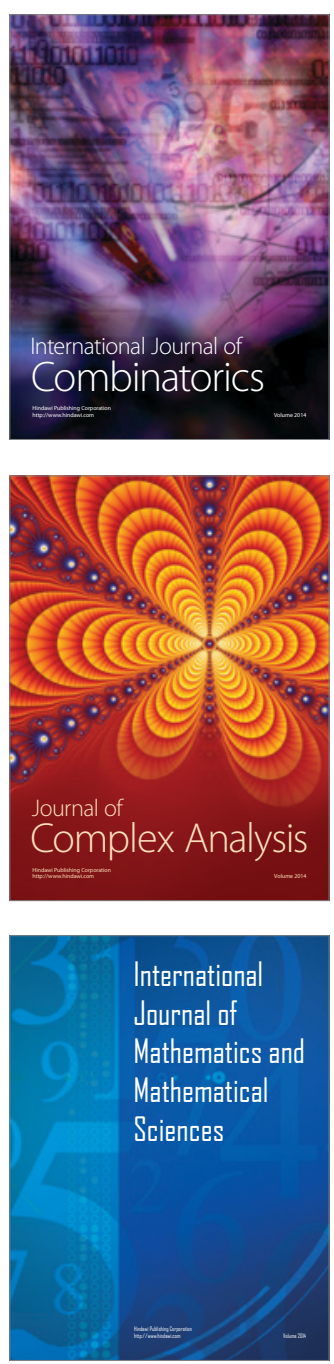
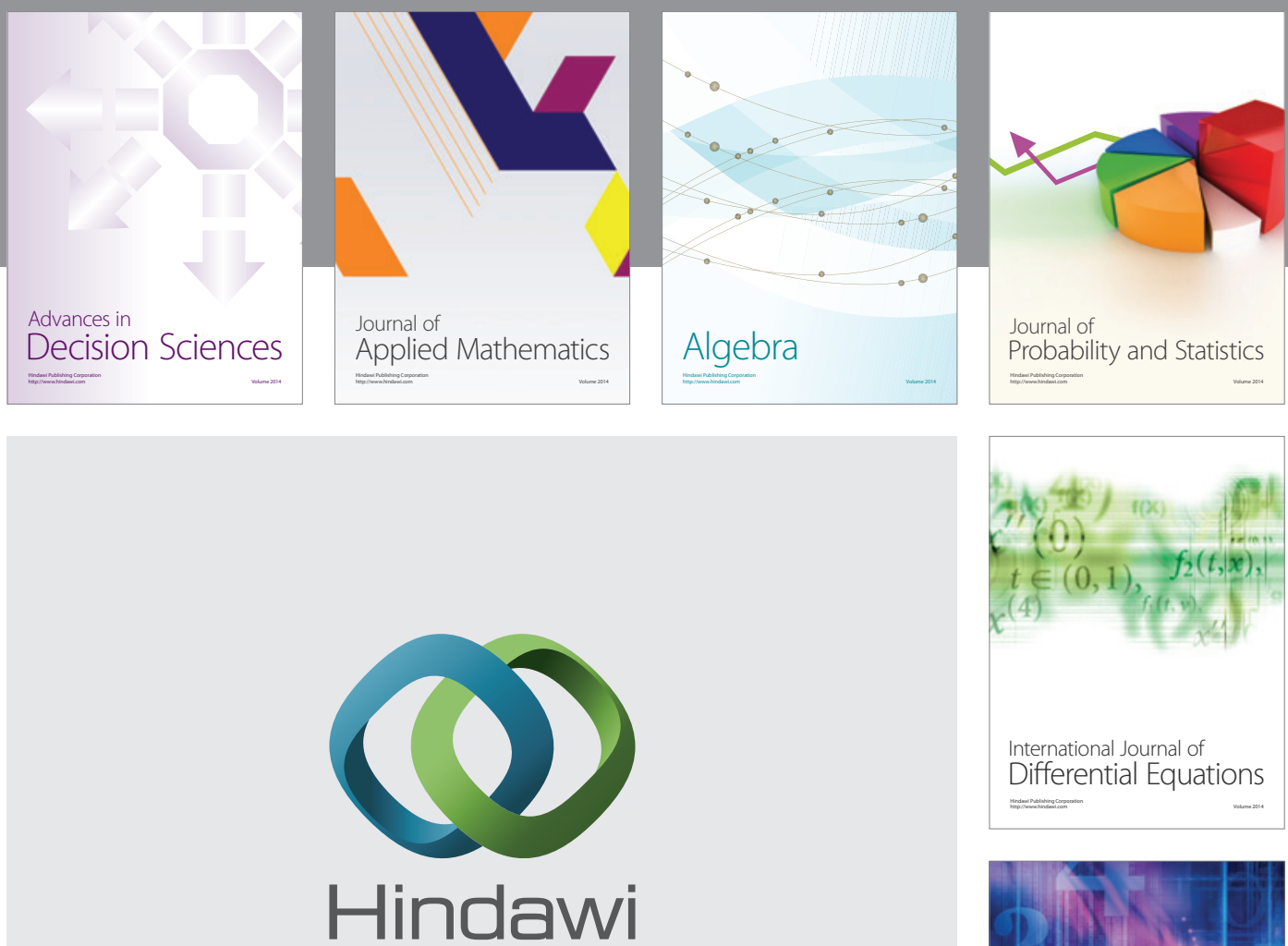

Submit your manuscripts at http://www.hindawi.com
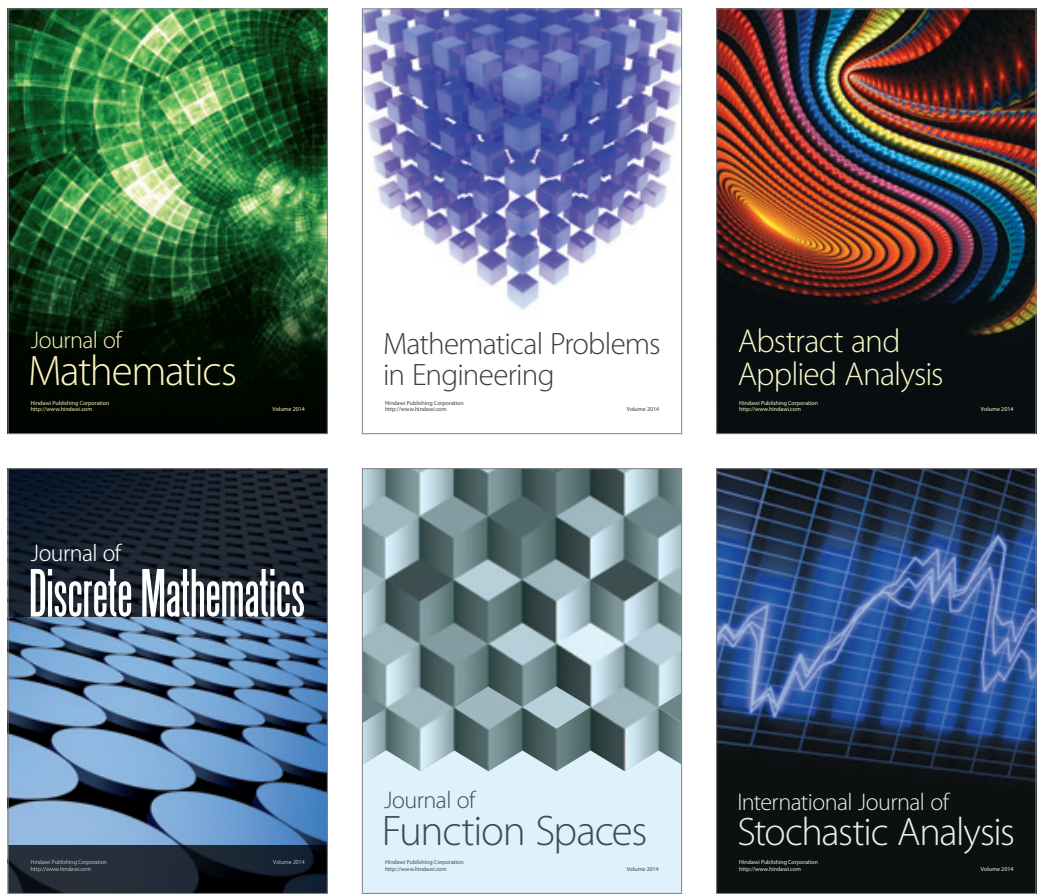

Journal of

Function Spaces

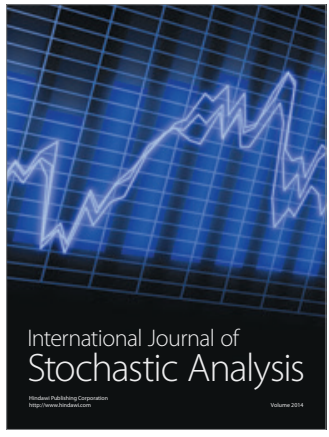

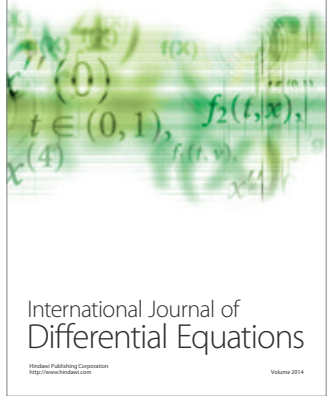
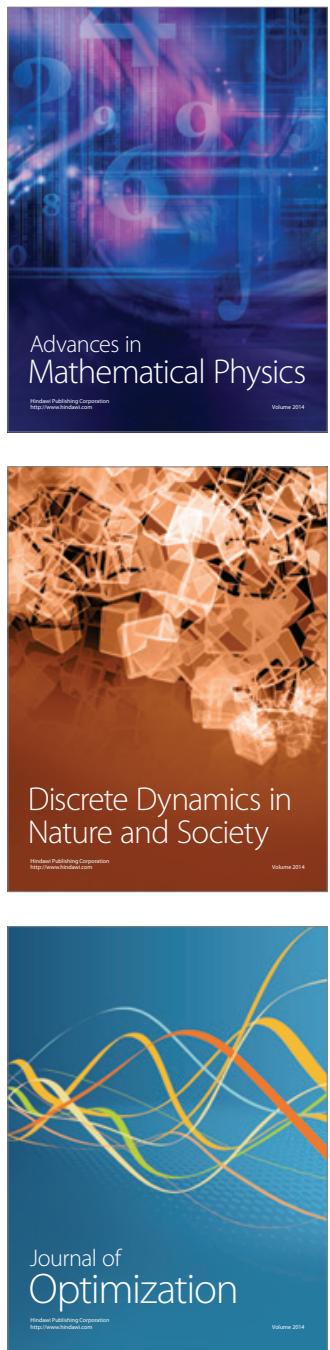